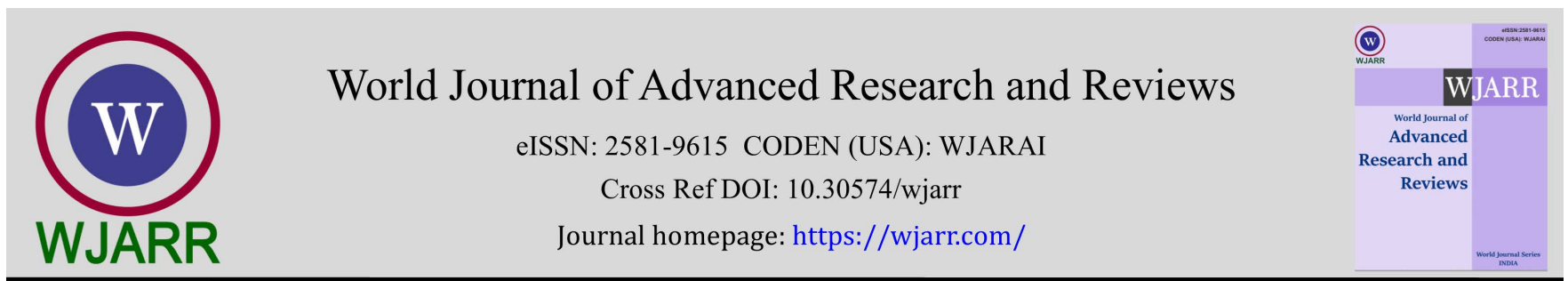

(RESEARCH ARTICLE)

Check for updates

\title{
Improvement of yield in Guizotia abyssinica (L.F.) Cass. by using backcross method
}

\author{
Vaibhav D Misal*, Sunaina S Davane and Shrikant B Mane \\ Cytology and Genetics Research laboratory, Department of Botany, Dr. Babasaheb Ambedkar Marathwada University, \\ Aurangabad - 431004, Maharashtra, India.
}

World Journal of Advanced Research and Reviews, 2021, 12(02), 261-266

Publication history: Received on 03 October 2021; revised on 09 November 2021; accepted on 11 November 2021

Article DOI: https://doi.org/10.30574/wjarr.2021.12.2.0579

\begin{abstract}
Guizotia abyssinica (L.F.) Cass. is one of the important oilseed crops cultivated in India. The seed of the plant is used by the tribal and rural people of our country as a source of edible oil. The present investigation of the Niger plant deals with the study of the back cross-program and improvement in the variety. Unknown local variety (A) of niger was selected as a non-recurrent parent because of having some desirable characters like less vegetative growth (dwarf), resistance to waterlogged condition, and large seed grains while IGP-76 variety (B) was selected as a recurrent parent and used as a female having characters like small black grains, resistant to leaf-eating cater Piller and powdery mildew result shows successfully transfer of the characters in the F1 generation. The average number of capitulum/plant shows very good and positive results in F1 as well as BC1 generation. As compared to the recurrent parent (B) an average number of capitulum per plant was increased in F1 generation by $14.28 \%$ and in $\mathrm{BC} 1$ generation by $28.5 \%$. The table indicates that there is incensement in the average number of seeds per capitulum. The average number of seeds per capitulum was increased by $8.3 \%$ in the $\mathrm{F} 1$ generation and by $11.11 \%$ in the $\mathrm{BC} 1$ generation as compared to the recurrent parent. Average weights of 1000 seeds were also increased in F1 generation by $31.78 \%$ and in $\mathrm{BC} 1$ generation by $47.28 \%$ along with the total yield per plant.
\end{abstract}

Keywords: Niger; Parent; Back cross; F1 generation; Production

\section{Introduction}

Guizotia abyssinica (Niger seed) belongs to the family Asteraceae. Niger or karala (Guizotia abyssinica) is an economically important edible oilseed crop. It is an important minor oilseed crop having medicinal properties mainly grown in India and Ethiopia [1]. It is also known by several names like Noug, Niger, Nyger, Nyjer, Khursani, Karala, etc. The seed of the plant is used by the tribal and rural people of India and Ethiopia as a source of edible oil. Some of the remote peoples also used the various part of the plant in the treatment and management of various microbial and inflammations conditions. Seeds are used by tribal people to treat the Rheumatoid by application of seed oil [2]. The oil is applied to the body parts to relieve pain, itching, swelling and inflammation, boils, etc. The seed is warmed in a kettle over an open fire, crushed with a pestle in a mortar, and then mixed with crushed pulse seeds to prepare 'wot' in Ethiopia [3]. The seed contains about $40 \%$ oil with a fatty acid composition of 75-80\% linoleic acid, 7-8\% palmitic and stearic acids, and 5-8\% oleic acid [4].

Niger seed oil is used in the preparation of various food articles, paint, and soap. Niger seed crop is a good precursor for cereals, pulses, and oilseeds because crops following Niger seed have less weed infestation [2]. It is one of the species found in India in cultivation status as such the species is vulnerable and going to disappear very soon. There is a need to promote conservation and develop a new variety of underutilized and neglected Niger crops. Niger shows self-

\footnotetext{
${ }^{*}$ Corresponding author: Vaibhav D Misal

Cytology and Genetics Research laboratory, Department of Botany, Dr. Babasaheb Ambedkar Marathwada University, Aurangabad 431004, Maharashtra, India.

Copyright (C) 2021 Author(s) retain the copyright of this article. This article is published under the terms of the Creative Commons Attribution Liscense 4.0.
} 
incompatible nature and entomophilous mode of pollination and hence it is very easy to go for the back cross method. The back cross method was first proposed by Harlan and Pope [5]. Niger seed is an important source of protein, carbohydrate, vitamins, and fiber that significantly contributes to the human diet.

India is the major producer of niger in the Asian continent, where 90 kilotons of niger seeds were produced during the 2011/2012 growing season [6]. Niger is also cultivated on small scale in several other African (Sudan, Uganda, Congo, Tanzania, Malawi, and Zimbabwe) and Asian (Nepal, Bangladesh, and Bhutan) countries [7, 8, and 4], where it accounts for a considerable proportion of edible oil production. In India, niger is predominantly grown in tribal pockets of Madhya Pradesh, Orissa, Chhattisgarh, Maharashtra, Andhra Pradesh, and Karnataka. The productivity of niger in India is low, around 300-350 $\mathrm{kg} \mathrm{ha}^{-1}$. Niger production during 2012-2013 has increased by 10\% and productivity by $86 \%$, even after a reduction of $41 \%$ in areal extent since 1965-1966. A total of 1600 niger germplasms are available for utilization in India. The cropping sequences and intercropping combinations with niger are different in different. An integrated nutrient management strategy, to increase the efficiency of fertilizer use, is being developed. Yield losses, due to various diseases and insect pests in different states, have been assessed and a management schedule for major diseases (Cercospora leaf spot, Alternaria leaf spot, and Macrophomina stem/root rot and powdery mildew) and insect pests (niger caterpillar, niger capsule fly, cutworms, semi looper, Bihar hairy caterpillar, and aphids) [9].

Niger, G. abyssinica, is a diploid $(2 \mathrm{n}=2 \mathrm{x}=30)[10,11]$ oil crop species in the Asteraceae family. It is an annual crop with a capitulum that consists of six to eight fertile female ray florets and 40-60 hermaphroditic disk florets [4]. The corymbs cymes of heads, 5 broadly ovate-obovate outer involucral leaves, 5-nerved paleae, and bigger achenes, are its main distinguishing characters from other Guizotia species [1]. Niger is a strictly outcrossing species with a sporophytic selfincompatibility mechanism [12,13], and is mainly pollinated by insects [14]. Sexual hybrids can easily be obtained from crosses between niger and its closely related wild relatives (15), including its progenitor G. scabra (Vis.) Chiov. ssp. Schimperi (Sch. Bip.) [1 and 16]. The back cross method was first proposed by Harlan and Pope (1922) and used particularly for transferring a simply inherited character like disease, frost or drought resistance, and earliness from an undesirable variety to a good commercial variety. The desirable variety is called a recurrent or recipient parent and it is crossed to an undesirable variety, called a donor or non-recurring parent. An F1 hybrid is obtained by crossing between recurrent and non-recurrent parents. To obtain a new variety F1 hybrid is repeatedly back cross with the recurrent parent. Niger is a completely outcrossing species with a self-incompatibility mechanism [17] and insects, particularly bees, are the major agents of pollination [18]. The self-incompatibility nature of Niger complicates the production of selfed seed. At Holetta, 600 accessions were tested for their ability to produce selfed seed using muslin cloth bagging [19]. As Niger shows self-incompatible nature and entomophilous mode of pollination, it is very easy to go for the back cross method.

This method is used particularly for transferring a simply inherited character like disease, frost, or drought resistance and earliness from an undesirable variety to a good commercial variety. The desirable variety is called a recurrent or recipient parent and it is crossed to an undesirable variety, called a donor or non-recurring parent. An $F_{1}$ hybrid is obtained by crossing between recurrent and non-recurrent parents. To obtain a new variety $F_{1}$ hybrid is repeatedly back cross with the recurrent parent.

\section{Material and methods}

The experiment was conducted in the Department of Botany, Dr. B.A.M. University, Aurangabad. The authors have selected two different varieties namely IGP-76 and unknown (local) of Guizotia abyssinica (Niger). Unknown variety was labeled as (A) and considered as a male parent while IGP-76 was labeled as (B) and considered as the female parent for the further experiment. The authors followed the standard protocol and important basic steps in backcross as shown in photo plate 1 .

\subsection{Selection of parents}

Unknown local variety (A) was selected as a non-recurrent parent and used as a male because of having some desirable characters like less vegetative growth (dwarf), resistance to waterlogged condition, and large seed grains. IGP-76 variety (B) was selected as a recurrent parent and used as a female having characters like small black grains, resistance to leaf-eating cater Piller, and powdery mildew. 


\subsection{Emasculation}

As the flowers of the plants were enough large, the authors preferred to hand emasculation. Corolla of the selected disc floret flowers did open in (B) and anthers were carefully removed with the help of fine-tip forceps. The emasculation was carried out early in the morning between 6.30-7.00 am.

\subsection{Bagging}

Immediately after emasculation, the inflorescences were enclosed in suitable butter paper bags of appropriate size. Those bags were removed 2-3 days after the pollination.

\subsection{Tagging}

The emasculated flowers were tagged just after the bagging. In the forgiven study, rectangular tags of size $3 \mathrm{x} 2 \mathrm{~cm}$ were used. The information like date of emasculation, date of pollination, time was recorded on it. The name of the parental varieties was also mentioned on the tags.

\subsection{Pollination}

Freshly collected pollens from the mature anthers of (A) were used for the pollination purpose. Fresh pollen grains were collected in a paper bag. With the help of a camel hair brush, collected pollen grains were dusted on the emasculated flowers and again enclosed with the help of a butter paper bag to avoid the chances of undesirable pollination.

\subsection{Harvesting of $F_{1}$ seed}

After maturity, dried plants are pulled out from the soil. Flowers were threshed with the help of a stick. The husk was removed and seeds were collected. That collected seeds were sun-dried and stored properly.

\subsection{Back Cross $1\left(\mathrm{BC}_{1}\right)$}

The stored $F_{1}$ seeds and (B) were again sowed. $F_{1}$ seeds were taken as male parent while (B) as a female. $F_{1}$ was backcrossed with the (B). The whole procedure of crossing $F_{1}$ with (B) was followed as mentioned above.

\subsection{Harvesting of $\mathrm{BC}_{1}$ seeds}

Plants that show similarities with (A) were selected and pulled out from the soil, threshed and husk was removed. Collected seeds were dried and stored properly (photo plate 2). Based on different parameters results and conclusions were drawn.

\section{Results and discussion}

The present investigation of the Niger plant deals with the study of the back cross-program and improvement in the variety. During the investigation, interesting results were obtained. Data relating to Percentage of seed germination, Average plant height $(\mathrm{cm})$, Average number of Capitulae per plant, Average number of seeds per Capitulum, Weight of 1000 seeds (gm.), and Average yield per plant (gm.) in Local variety (A), IGP-76 (B), $F_{1}$ generation and $\mathrm{BC}_{1}$ generation are presented in Table1. It is clear from the table that the rate of percentage of seed germination remains the same as a recurrent parent (B) in the $F_{1}$ generation and $\mathrm{BC} 1$ generation. The average plant height in the $F_{1}$ generation and $\mathrm{BC}_{1}$ generation slightly decreased as compared to the recurrent parent. As non-recurrent parent was dwarf, the result shows the successful transfer of the characters in the $F_{1}$ generation. The average number of Capitulum/plant shows very good and positive results in $F_{1}$ as well as BC1 generation. As compared to the recurrent parent (B) the average number of Capitulum per plant was increased in $F_{1}$ generation by $14.28 \%$ and in $\mathrm{BC}_{1}$ generation by $28.5 \%$. The table indicates that there is increasement in the average number of seeds per capitulum. The average number of seeds per Capitulum was increased by $8.3 \%$ in the $F_{1}$ generation and by $11.11 \%$ in $\mathrm{BC}_{1}$ generation as compared to the recurrent parent. Average weights of 1000 seeds were also increased in $F_{1}$ generation by $31.78 \%$ and in $\mathrm{BC}_{1}$ generation by $47.28 \%$ along with the total yield per plant. There were very satisfying results obtained in average yield per plant. The average yield per plant was increased from $0.5 \mathrm{gm}$. to $0.8 \mathrm{gm}$. in $\mathrm{BC} 1$ generation. It was clear that the average yield per plant increased by $40 \%$ in the $\mathrm{F} 1$ generation and by $60 \%$ in the $\mathrm{BC}_{1}$ generation. From the above results, the authors concluded that nearly about $50 \%$ of the higher-yielding characters were transferred from the variety (A) to variety (B). To transfer $100 \%$ character from one plant to another plant and release it as a new variety, 6-7 backcrosses are needed. In agreement to high yield traits of Niger Getinet and Sharma [4] who viewed niger as an admirable trait for the development of hybrid. Remarkably, both the inbred lines and their hybrids developed by Geleta and Bryngelsson [13] showed synchronized maturity, which is one of the highly desirable traits in niger. Therefore, a strategy for hybrid breeding based on inbred 
lines may lead to an increase in seed yield in niger. Planting of different lines in alternate rows in the field will result in the production of both self-and hybrid seeds in the first generation. In the following generation, hybrids and parental lines can be manually harvested separately, as they are morphologically easily distinguishable due to the fact that hybrids show hybrid vigor [13].

Table 1 Comparative analysis of observed characters in local variety (A), IGP-76(B), $F_{1}$ generation, and $\mathrm{BC}_{1}$ generation

\begin{tabular}{|c|l|c|c|c|c|}
\hline Sr. No. & \multicolumn{1}{|c|}{ Observed characters } & $\begin{array}{c}\text { Local } \\
\text { Variety(A) }\end{array}$ & IGP-76 (B) & $\begin{array}{c}\text { (A) x (B) } \\
\boldsymbol{F}_{\mathbf{1}} \text { generation }\end{array}$ & $\begin{array}{c}\boldsymbol{F}_{\mathbf{1}} \mathbf{x} \text { (B) } \\
\mathbf{B C}_{\mathbf{1}}\end{array}$ \\
\hline 1 & $\begin{array}{l}\text { Percentage of seed } \\
\text { germination }\end{array}$ & $70 \%$ & $80 \%$ & $80 \%$ & $80 \%$ \\
\hline 2 & $\begin{array}{l}\text { Average plant height (cm) } \\
\text { Capitulae/plant }\end{array}$ & 52 & 60 & 56 & 57 \\
\hline 4 & $\begin{array}{l}\text { Average number of } \\
\text { Capitulum }\end{array}$ & 29 & 36 & 39 & 27 \\
\hline 5 & $\begin{array}{l}\text { Weight of 1000 seeds } \\
\text { gm.) }\end{array}$ & 3.3 & 2.58 & 3.4 & 3.8 \\
\hline 6 & Average yield/plant (gm.) & 0.8 & 0.5 & 0.7 & 0.8 \\
\hline
\end{tabular}

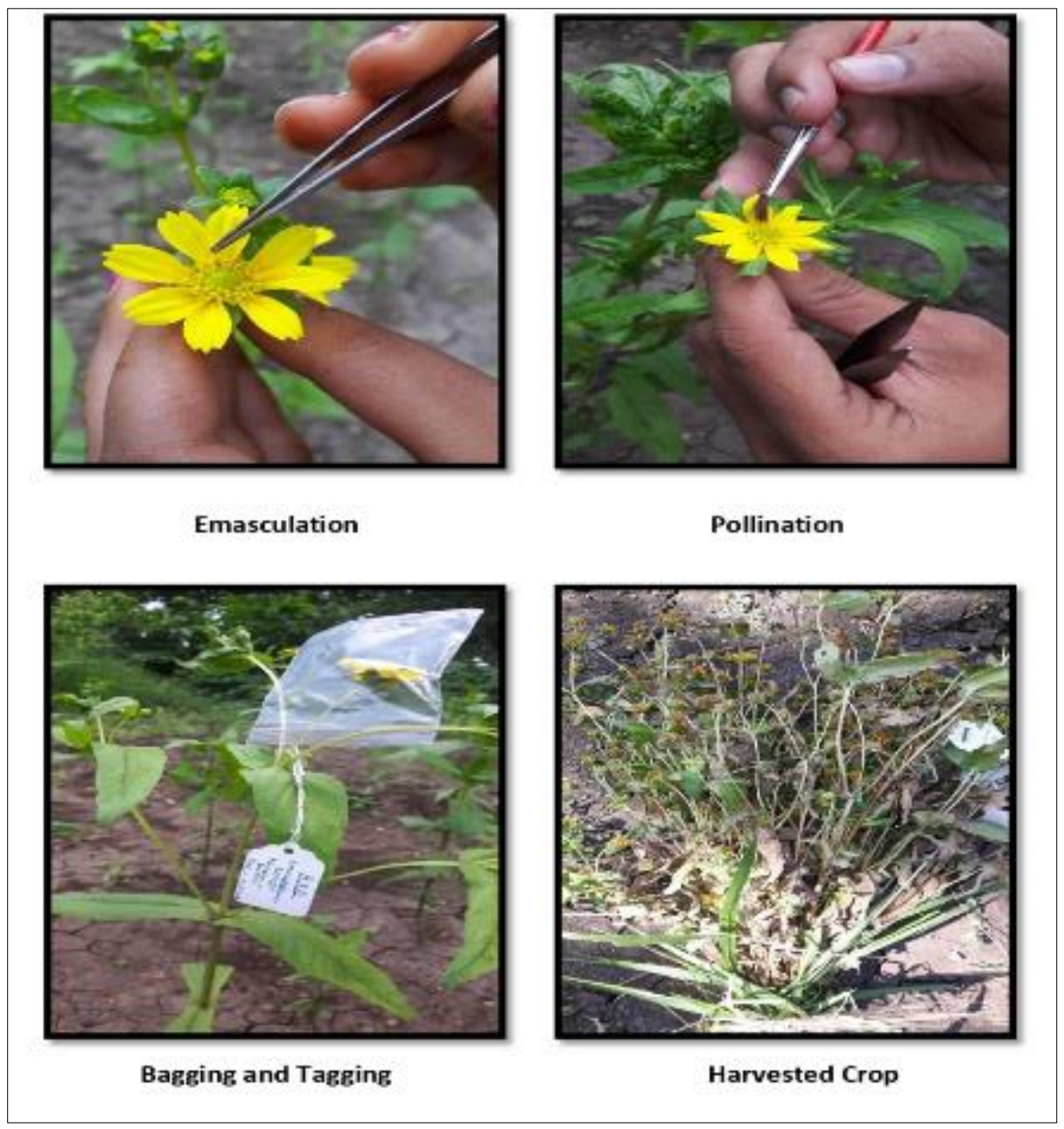

Figure 1 Steps of hybridization involved in back cross programme 


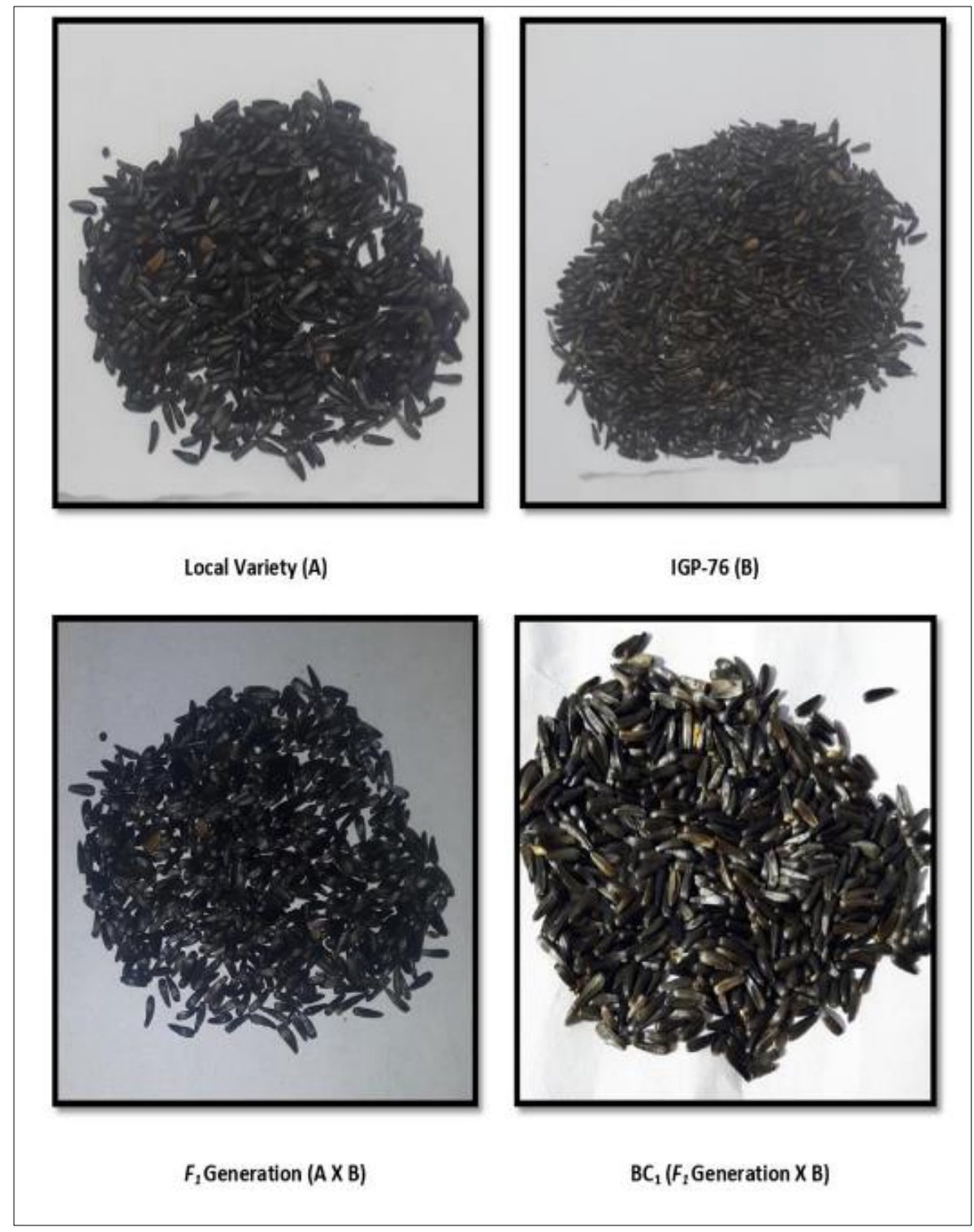

Figure 2 Harvested seeds of $\mathrm{F}_{1}$ and back cross generation along with parents, Local Variety (A) and IGP-76 (B)

\section{Conclusion}

It was important need towards the high yielding hybrids of Guizotia abyssinica to concentrate cultivars for Niger cultivation from the recent research findings it is clearly shown from the backcross breeding method that the potential of this crop has not been fully exploited, and its contribution towards sustainable food security is far lower Guizotia abyssinica potential. Niger has a wide genetic diversity in India, and traits of interest can easily be found. The utilization of this wealth of genetic resources ensures direct contributions to sustainable agricultural development in the country through the provision of superior genetically developed traits adequate focus impact on sustainable agriculture as well food security to the human community.

\section{Compliance with ethical standards}

\section{Acknowledgments}

The authors are thankful to the senior professor Dr. A. M. Chavan for their valuable guiding; to Dr. A. S. Dhabe, Professor and Head of Department of Botany for providing all the facilities. Prof. Ashok. M. Chavan and late Prof. N. B. Pandhure for helping hand giving moral support and providing literature. Mr. B. S. Dhokne for color plates. 


\section{Disclosure of conflict of interest}

This statement is to certify that all Authors have seen and approved the manuscript being submitted. We warrant that the article is the Authors' original work. We warrant that the article has not received prior publication and is not under consideration for publication elsewhere. On behalf of all Co-Authors, the corresponding Author shall bear full responsibility for the submission. All authors agree that author list is correct in its content and order and that no modification to the author list can be made without the formal approval of the Editor-in-Chief, and all authors accept that the Editor-in-Chief's decisions over acceptance or rejection or in the event of any breach of the Principles of Ethical Publishing in the World Journal of Advanced Research and Reviews being discovered of retraction are final.

\section{References}

[1] Baagøe J. 1974. The genus Guizotia (Compositae). A taxonomic revision. Bot. Tidsskrift. 1974; 69: 1-39.

[2] Adarsh MN, Poonam, Kumari, Shilpa, Devi. A review of Guizotia abyssinica: a multipurpose plant with an economic prospective. Jr. of Industrial Pollution Control. 2014; 30(2): 277-280.

[3] Seegeler CJP. Oil plants in Ethiopia. Their taxonomy and agricultural significance. Centre for Agricultural Publication and Documentation, PUDOC, Wageningen. 1983.

[4] Getinet A, Sharma SM. Niger (Guizotia abyssinica (L. f.) Cass. Promoting the conservation and use of underutilized and neglected crops. vol 5. Institute of Plant Genetics and Crop Plant Research, Gatersleben/International Plant Genetic Resources Institute, Rome. 1996.

[5] Harry V Harlan, Merritt N Pope. The use and value of back-crosses in small-grain breeding, Journal of Heredity. 1922; 137: 319-322.

[6] IOPEPC. Indian oilseeds and produce export promotion council.

[7] Weiss EA. Oilseed crops. Longman Inc., New York. 1983.

[8] Murthy HN, Hiremath SC, Salimath SS. Origin, evolution and genome differentiation in Guizotia abyssinica and its wild species. Theor Appl Genet. 1993; 87: 587-592.

[9] ARG. Ranganatha, Anand Kumar, PandayRajani, Bisen SurabhiJain, and Shikha Sharma Breeding Oilseed Crops for Sustainable Production Opportunities and Constraints. 2016; 169-199.

[10] Dagne K, Heneen WK. The karyotype and nucleoli of Guizotia abyssinica (Compositae). Hereditas. 1992; 117: 7383.

[11] Dagne K Karyotypes, C-banding and nucleolar numbers in Guizotia (Compositae). Plant Syst Evol. 1995; 195: $121-135$.

[12] Nemomissa S, Bekele E, Dagne K. Self-incompatibility system in Ethiopian populations of Guizotia abyssinica (L.f.) Cass. (niger). Sinet Ethiop J Sci. 1999; 22: 67-88.

[13] Geleta M, Bryngelsson T. (2010) Population genetics of self-incompatibility and developing self-compatible genotypes in Guizotia abyssinica (L. f.) Cass. (Asteraceae). Euphytica. 2010; 176: 417-430.

[14] Geleta M, Asfaw Z, Bekele E, Teshome A. Edible oil crops and their integration with the major cereals in North Shewa and South Welo, central highlands of Ethiopia: an ethnobotanical perspective. Hereditas. 1994; 137: 2940 .

[15] Dagne K. Meiosis in interspecific hybrids and genomic interrelationships in Guizotia Cass. (Compositae). Hereditas. 1994; 121: 119-129.

[16] Geleta M, Bryngelsson T, Bekele E, Dagne K. Phylogenetics and taxonomic delimitation of the genus Guizotia (Asteraceae) based on sequences derived from various chloroplast DNA regions. Plant Syst Evol. 1994; 289: 7789.

[17] Chavan VM. Niger and Safflower. Indian Central Oilseeds Committee, Hyderabad. 1961.

[18] Ramachandran TK, P Menon. Pollination mechanisms and inbreeding depression in niger (Guizotia abyssinica Cass.). Madras Agric. J. 1979; 66: 449-454.

[19] Riley KW, H Belayneh. Oil Crops of the World. McGraw Hill Publishing Company, New York. 1989; $394-403$. 